\title{
A Rare Case of Exocrine Pancreatic Insufficiency
}

\author{
Mohamed Labied, Houria Tabakh, Hamza Guezri, Abdellatif Siwane, Najwa Touil, Omar Kacimi, Nabil Chikhaoui \\ Emergency Radiology Department, Ibn Rochd University Hospital, Faculty of Medicine and Pharmacy of Casablanca, Morocco
}

Received: $10 / 04 / 2021$

Accepted: $13 / 04 / 2021$

Published: 18/05/2021

How to cite this article: Labied M, Tabakh H, Guezri H, Siwane A, Touil N, Kacimi O, Chikhaoui N. A rare case of exocrine pancreatic insufficency. EJCRIM 2021;8: doi:10.12890/2021_002556.

Conflicts of Interests: The authors declare there are no competing interests.

This article is licensed under a Commons Attribution Non-Commercial 4.0 License

\section{ABSTRACT}

Lipomatous pseudohypertrophy (LPH) of the pancreas is an uncommon affection of exocrine pancreatic insufficiency. It is defined as substitution of the pancreatic exocrine gland by a large fat component. We report the case of a young patient with malabsorption syndrome (chronic diarrhoea and steatorrhoea), abnormal laboratory results and normal fibroscopy. Computed tomography revealed characteristic diffuse pancreatic abnormalities.

\section{LEARNING POINTS}

- Computed tomography is key for identifying lipomatous pseudohypertrophy.

- Malabsorption syndrome is usually associated with lipomatous pseudohypertrophy.

- A syndromic aetiology should be considered.

\section{KEYWORDS}

Fat, pancreas, lipomatous pseudohypertrophy

\section{INTRODUCTION}

Lipomatous pseudohypertrophy (LPH) of the pancreas is a rare disorder defined by enlargement of the pancreas due to replacement of the exocrine parenchyma by adipose tissue. This disorder is very rare, with less than 100 cases reported in the literature. An association with cystic fibrosis, Shwachman-Diamond syndrome or Johanson-Blizzard syndrome has been reported.

\section{CASE DESCRIPTION}

We report the case of an 18-year-old female patient who was admitted for investigation of malabsorption syndrome because of significant weight loss, chronic diarrhoea (more than five greasy stools per day) and oedema of the lower limbs on clinical examination. Initial biological assessment found normochromic normocytic anaemia ( $8 \mathrm{~g} \mathrm{Hb} / \mathrm{dl}$ ) and steatorrhoea at 26g/24h. Gastrointestinal fibroscopy and abdominal ultrasound did not detect any abnormalities. However, an abdominal CT scan showed a lipomatous pancreas with a granular parenchyma, without ductal dilatation or abnormality of the peripancreatic fat (Fig. 1).

The diagnosis of LPH of the pancreas was confirmed and the patient was started on pancreatic enzyme replacement therapy with a favourable clinical and biological evolution. 


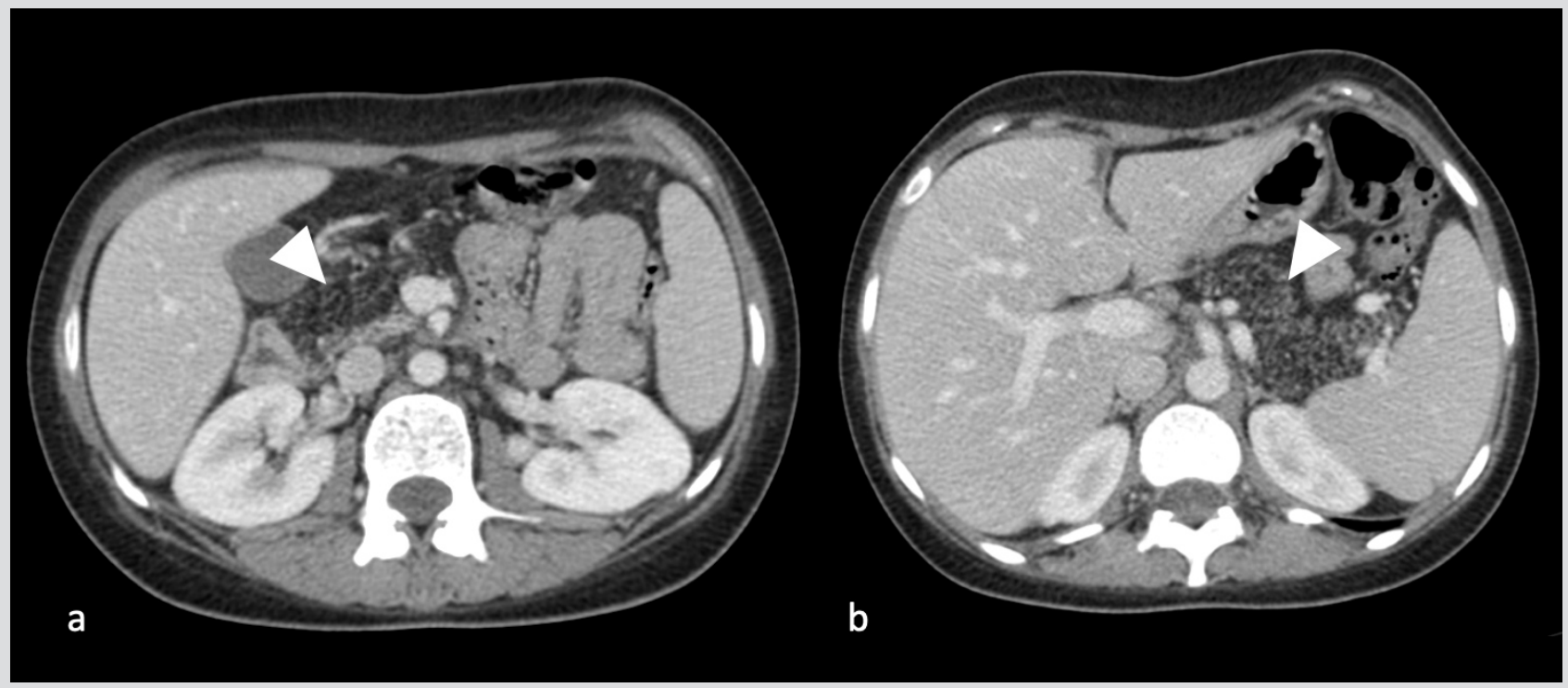

Figure 1. Contrast-enhanced computed tomography shows the fatty appearance of (a) the right side and (b) the left side of the pancreas with the parenchyma having a granular appearance (arrowheads). No ductal dilatation or abnormality of the peripancreatic fat was present

\section{DISCUSSION}

Lipomatous pseudohypertrophy of the pancreas, also called diffuse fatty infiltration of the pancreas, is a rare cause of exocrine pancreatic deficiency in adults ${ }^{[1]}$. It consists of accumulated adipocytes in the pancreatic parenchyma that replace the acini and islets of Langerhans ${ }^{[2]}$. The affected pancreas can vary greatly in size ${ }^{[3]}$. Lipomatous pseudohypertrophy has no effect on the endocrine function of the pancreas ${ }^{[4]}$ but, when it is massive, it can be associated with exocrine pancreatic insufficiency with steatorrhoea and malabsorption of the fat-soluble vitamins $\mathrm{A}, \mathrm{D}, \mathrm{E}$ and $\mathrm{K}^{[5]}$.

The most common cause of LPH is advanced cystic fibrosis ${ }^{[2]}$ but other diseases are also implicated, including Shwachman-Diamond syndrome, which is also associated with neutropenia, digestive disorders and metaphyseal bone chondrodysplasia (with failure to thrive) [5, 6], and with Johanson-Blizzard syndrome (autosomal recessive transmission), which is characterized by aplasia of the scalp and nasal alae, dental malformations, bilateral deafness and exocrine pancreatic failure ${ }^{[7]}$. A primitive form of LPH of the pancreas was hypothesized in patients who successfully regained weight with a reduction in steatorrhoea after treatment with pancreatic extracts ${ }^{[1]}$.

Imaging provides the diagnosis. Ultrasound shows a normal or enlarged pancreas. The echostructure depends on the degree of fat infiltration. This may be normal, more echogenic than the liver but less echogenic than the surrounding retroperitoneal fat, or even isoechoic to the latter ${ }^{[3,8]}$. On computed tomography, the pancreas appears increased in size and empty, with tissue replaced with a fat density component, which is similar to retroperitoneal fat with a granular-like appearance ${ }^{[9]}$. MRI shows a diffuse and homogeneous T1 and T2 hypersignal replacing the pancreatic parenchyma with signal suppression on fat saturation sequences ${ }^{[10]}$.

The most important differential diagnoses are pancreatic lipoma and retroperitoneal liposarcoma. Pancreatic lipomas are multilobed tumours that are sharply delineated from surrounding pancreatic tissue by a thin fibrous capsule ${ }^{[11]}$, while liposarcoma has a more infiltrative and voluminous appearance.

There is no established disease-specific therapy for LPH, but if symptoms of exocrine function insufficiency are present, digestive enzymes, such as pancreatic enzymes, are administered ${ }^{[2]}$.

\section{CONCLUSION}

This diagnosis is easily established by computed tomography imaging which shows a characteristic fatty infiltration of the pancreas. The most frequent cause is advanced cystic fibrosis with generally favourable evolution after pancreatic enzyme replacement therapy. 


\section{REFERENCES}

1. Aubert A, Gornet JM, Hammel P, Lévy P, O'Toole D, Ruszniewski P, et al. [Diffuse primary fat replacement of the pancreas: an unusual cause of steatorrhea]. Gastroenterol Clin Biol 2007;31(3):303-306.

Durie PR. Pancreatic aspects of cystic fibrosis and other inherited causes of pancreatic dysfunction. Med Clin North Am 2000;84(3):609-620.

Nakamura M, Katada N, Sakakibara A, Okumura N, Kato E, Takeichi M, et al. Huge lipomatous pseudohypertrophy of the pancreas. Am J Gastroenterol 1979;72(2):171-174.

Danovitch SH, Paley R, Mann O, Choisser R, Bayless T. Vanishing pancreas. Lipomatous infiltration of the pancreas. JAMA 1985;253(10):1442-1443.

Smith OP. Shwachman-Diamond syndrome. Semin Hematol 2002;39(2):95-102.

Dror Y, Freedman MH. Shwachman-Diamond syndrome. Br J Haematol 2002;118(3):701-713.

7. Maunoury V, Nieuwarts S, Ferri J, Ernst O. Lipomatose pancréatique révélatrice d'un syndrome de Johanson-Blizzard [Pancreatic lipomatosis revealing Johanson-Blizzard syndrome]. Gastroenterol Clin Biol 1999;23(10):1099-1101.

8. Worthen NJ, Beabeau D. Normal pancreatic echogenicity: relation to age and body fat. AJR Am J Roentgenol 1982;139(6):1095-1098.

9. Heuck A, Maubach PA, Reiser M, Feuerbach S, Allgayer B, Lukas P, et al. Age-related morphology of the normal pancreas on computed tomography. Gastrointest Radiol 1987;12(1):18-22.

10. Guermazi A, Benchaib N, Nolen N, Tabti B, Zagdanski AM. Fatty replacement of the pancreas in a patient with asymptomatic pulmonary cystic fibrosis. J Radiol 2003;84(4 Pt 1):409-411.

11. Boglino C, Inserra A, Silvano A, Ciprandi G, Boldrini R, Caione P. Intrapancreatic lipoma: a case report (in Italian). Pediatr Med Chir 1993;15(4):397-399.

12. Ueki T, Mizuno M, Nakagawa M, et al. A case of diffuse fatty replacement of the pancreas which guessed lipomatous pseudohypertrophy of the pancreas (in Japanese). Tan to Sui 2006;27:259-262. 